\title{
COVID-19 Patient Health Monitoring System
}

\author{
Anurag Tatkare, Hemangi Patil, Tejal Salunke, Shreya Warang, Dipak Marathe \\ A.C. Patil College of Engineering, Kharghar, 410210, India \\ E-mail: anuragtatkare@gmail.com, hemangipatil468,_ salunketejal97, warangshreya@gmail.com, \\ dsmarathe@acpce.ac.in
}

Received: 20 July 2021; Accepted: 27 August 2021; Published: 08 October 2021

\begin{abstract}
The system proposed can be used to regular checkup of the COVID patients while maintaining the social distancing. Also, the data sensed by the sensors is directly sent to doctor, reducing the cost of paying regular visits to doctor. The Iot platform used in the system helps to transfer the real time patient's data remotely to host device. Daily health record can be maintained and can be viewed easily on graphs charts ease for doctors to see any abrupt changes in oxygen level or rise in temperature. To track the patient health micro-controller is in turn interfaced to an LCD display and wi-fi connection to send the data to the web-server (wireless sensing node). In case of any abrupt changes in patient heart-rate or body temperature alert is sent about the patient using IoT. This system also shows patients temperature and heartbeat tracked live data with timestamps over the Internetwork.
\end{abstract}

Index Terms: Heart beat rate (BPM), Blood Oxygen (SpO2), Pulse Oximeter, Temperature sensor, Internet of Things (IoT), Blynk.

\section{Introduction}

The world is facing pandemic situation due to Corona virus. This virus spreads easily even through normal human interactions. The increase in COVID patients has also led to decrease in the relative number of doctors per patient as a solution for this the patients with minor symptoms are home quarantined. In such situation maintaining personal health and immunity is very important for a home quarantined patient without being regularly monitored by the doctors. Recently, the patient monitoring systems is one of the major advancements because of its improved technology. Currently, there is need for a modernized approach. They need to visit the patient's ward for necessary diagnosis and advising. Firstly, the healthcare professionals must be present on site of the patient all the time and secondly, the patient remains admitted in a hospital, bedside biomedical instruments, for a period of time. The problem with this traditional approach is that there are chances of getting doctors and health personnel affected with the

COVID due to coming in contact with contagious patient. In order to solve these two problems, the patients are given knowledge. In order to improve the above condition, we can make use of technology in a smarter way. In recent years, health care sensors and advanced microcontrollers play a vital role to detect and monitor human body physiological parameters. In our system we to solve these two problems, the patients are given knowledge and information about disease diagnosis and prevention. Secondly, a reliable and readily available patient monitoring system is required. In order to improve the above condition, we can make use of technology in a smarter way. In recent years, health care sensors advanced microcontrollers play a vital role. Contact with the human body and monitor his or her physiological parameters. In our system we are measuring patient's parameters (temperature, heart rate, pulse, etc.) with different available sensors. These sensors collected data i.e., biometric information is given to raspberry pi and then it is transferred to server. In section II and III, Objective and Methodology of the project is discussed. Section IV consists of COVID Patient Health Monitoring Device design; simulation and its implementation are discussed. The results and discussions are mentioned in section $\mathrm{V}$. Table1 shows the literature survey done.

\section{Objective}

The personal health monitoring of each individual is considered very important for a home quarantined patient. Moreover, the increase in COVID patients has also leads to decrease in the relative number of doctors per patient which results in vicious cycle where ignored or delayed diagnostics of an aliment makes the patient more dependent on doctor checkup. Though it is advisable to visit the doctor but as discussed above if the patient is home quarantined or if due to unavailability of specialist due to some reason, the health monitoring devices offer an effective alternative. Thus, there is need for software that utilizes the data available from the device, uploads it to the website, and gets feedback from doctors via internet and show health reports. Doctor should be able to get data anytime he wants for analysis. The health 
monitoring device can record various data like patient's heart beat rate, oxygen level; body temperature while in being in contact with the patient and this data from patient can be used by physicians to recommend any changes to patient's routine and medicines.

The main objective is to design a Remote Patient Health Monitoring system to diagnose health condition of the patients without coming in close contact with the patient. Giving care and health assistant to a COVID patient in this pandemic situation has become one of major problems as the doctors, nurses, medical staff are also getting this virus due to coming in contact with contagious patient their lives are also in risks. Proper implementation of such health monitoring system can provide a safer way to diagnose a home quarantined patient where physical conditions of the patient can be monitored frequently, the need for cost effective and fast responding alert mechanism is inevitable. The Internet of Things (IoT) platform offers a promising technology to achieve the healthcare services, and can further improve the medical service systems. IoT wearable platforms can be used to collect the needed information of the patient and communicate such information wirelessly, where it is processed or stored for tracking the history of the patient.

\section{Literature Survey}

Table 1. Literature survey patient health monitoring system.

\begin{tabular}{|l|l|l|l|l|}
\hline \multicolumn{1}{|c|}{ Ref. } & \multicolumn{1}{c|}{ Title } & \multicolumn{1}{c|}{ Author } & \multicolumn{1}{c|}{ Conclusion } & \multicolumn{1}{c|}{ Drawbacks } \\
\hline $\begin{array}{l}\text { Int. Conf., } \\
\text { March 2015 }\end{array}$ & $\begin{array}{l}\text { Design of Mobile Healthcare } \\
\text { Monitoring System Using IoT } \\
\text { Technology and Cloud Computing }\end{array}$ & $\begin{array}{l}\text { Mustafa A Al-Sheikh } \\
\text { and Ibrahim A Ameen }\end{array}$ & $\begin{array}{l}\text { Capable to monitor } \\
\text { more than one health } \\
\text { parameter. }\end{array}$ & $\begin{array}{l}\text { No proper layout of ECG. } \\
\text { Unreliable. }\end{array}$ \\
\hline $\begin{array}{l}\text { Journal, March } \\
2018\end{array}$ & $\begin{array}{l}\text { Monitoring of Patients Through Pulse } \\
\text { \& Heart Rate Sensor }\end{array}$ & $\begin{array}{l}\text { Ajith, Praveen raj, Syed } \\
\text { Ibrahim, Mr. Nagaraj }\end{array}$ & $\begin{array}{l}\text { Measuring heart rate, } \\
\text { temperature and oxygen } \\
\text { level. }\end{array}$ & $\begin{array}{l}\text { False Alarm generated in } \\
\text { case of battery issue. }\end{array}$ \\
\hline $\begin{array}{l}\text { IEEE Journal, } \\
\text { Sept. 2019 }\end{array}$ & $\begin{array}{l}\text { A Home Telemedicine System for } \\
\text { Continuous Respiratory Monitoring }\end{array}$ & $\begin{array}{l}\text { Alessandra Angelucci, } \\
\text { David Kuller }\end{array}$ & Real time monitoring. \\
\hline $\begin{array}{l}\text { IEEE Journal, } \\
\text { July 2020 }\end{array}$ & $\begin{array}{l}\text { Organic Multi-Channel } \\
\text { Optoelectronic Sensors for Wearable } \\
\text { Health Monitoring }\end{array}$ & $\begin{array}{l}\text { Yasser Khan, } \\
\text { Donggeon han, } \\
\text { Jonathon Ting }\end{array}$ & $\begin{array}{l}\text { Only oxygen level } \\
\text { detection. }\end{array}$ & $\begin{array}{l}\text { Lacks wireless } \\
\text { communication and } \\
\text { temperature sensor. }\end{array}$ \\
\hline $\begin{array}{l}\text { IEEE Journal, } \\
\text { Oct 2018 }\end{array}$ & $\begin{array}{l}\text { A Wearable Pulse Oximeter with } \\
\text { Wireless Communication and Motion } \\
\text { Artifact Tailoring for Continuous Use }\end{array}$ & $\begin{array}{l}\text { Pedro J. Chacon, Tallis } \\
\text { H. da Costa, Taher } \\
\text { Ghomian, }\end{array}$ & $\begin{array}{l}\text { Oxygen level in low } \\
\text { noise detected. }\end{array}$ & $\begin{array}{l}\text { Bluetooth network used. } \\
\text { No temperature sensor }\end{array}$ \\
\hline $\begin{array}{l}\text { Int. Conf., } \\
\text { March 2018 }\end{array}$ & $\begin{array}{l}\text { Synchronized Intermittent Mandatory } \\
\text { Ventilation Mode Control Using Pulse } \\
\text { Oximeter }\end{array}$ & $\begin{array}{l}\text { Tassadaq Hussain, } \\
\text { Amna Haider, Wasim } \\
\text { Akram }\end{array}$ & $\begin{array}{l}\text { Different oximeter } \\
\text { techniques discussed. }\end{array}$ & $\begin{array}{l}\text { Only oxygen level } \\
\text { measuring technique } \\
\text { discussed. }\end{array}$ \\
\hline
\end{tabular}

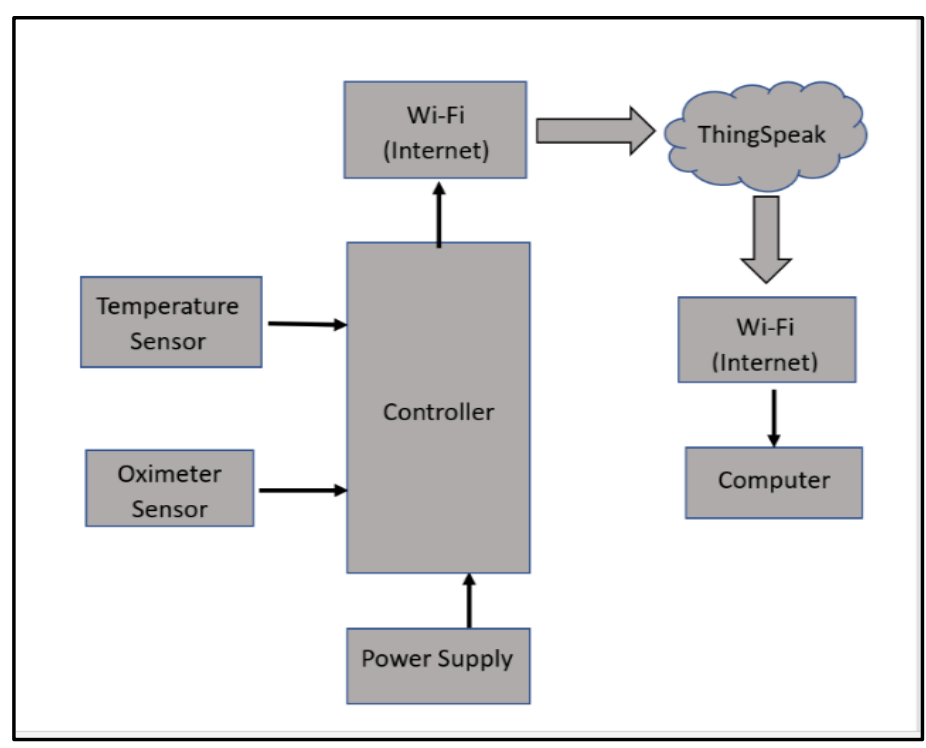

Fig. 1. Block diagram of covid patient health monitoring system 


\section{Methodology}

This device uses oximeter sensor and temperature sensor which gives the proper values to the controller. Generally, in normal condition SpO2 ranges form 95- 97 and temperature from 36-37. The values recorded are uploaded to Blynk so they can be viewed from anywhere using internet. The person must practice hand hygiene - wash hands for at least 20seconds. Place a fingertip on MAX30100 Oximeter sensor and also place a finger on LM35 Temperature sensor. The sensors start recording the data and send it to Node MCU. The Node MCU transmits the data to the mobile phone using the Wi-Fi module. In the Blynk app 2 labeled value widget and 1 Super Chart is used to display the data. This data is received by the mobile using the internet and displayed in the Blynk app. The normal body temperature ranges from 36$38^{\circ} \mathrm{C}$ and the oxygen level ( $\mathrm{SpO} 2$ ) level ranges from 95-98\%. If the readings are above or below this range for a long time then the patient requires medical attention. Accordingly, the medical staff will take further actions.

\section{Designing and Simulation of Covid Patient Health Monitoring Device}

The proposed block diagram of the system is as follows. With help of this project doctors can diagnose the patient remotely and can record patient's health status. In this project the controller will take the input from the temperature sensor and also from the Heart beat sensor. The inputs will be in electrical form. Then the controller will process the inputs and the signal will be transmitted using the Wi-Fi module. The PC or laptop is used for recording all the data that is received through device1. The data is received via internet. The data is registered on the Blynk using internet. Proposed System consists of following Sensors and Microcontroller [1] ESP-32 is one of the main IoT learning tools. EPS32 can communicate with other Wi-Fi and Bluetooth devices via its SPI/SDIO, or I2C/UART interfaces. [2] The LM35 series are accurate optimized temperature circuits with output voltage, which is linearly relative to the temperature in centigrade. The LM35 has advantage over Kelvin's linear temperature sensors. The huge constant voltage from the display does not allow the consumer to delete in the realistic centigrade scaling. [3] MAX30100 Pulse Oximeter works on principle of pulse oximeter is based on the differential absorption characteristics of oxygenated and the de-oxygenated hemoglobin. Using this information, the microcontroller determines concentration of oxyhemoglobin $(\mathrm{HbO} 2)$ and concentration of deoxyhemoglobin $(\mathrm{Hb})$.

\section{The $\%$ of oxyhemoglobin $=$ $\mathrm{HbO} 2 / \mathrm{HbO} 2+\mathrm{Hb}$}

The controllers $3 \mathrm{~V}$ and GND pin are connected to VCC and GND pin of both the sensors. This provides supply to them. The SCL and SDA pins of Pulse Oximeter are connected to SCL and SDA pins of controller. They help in communicating with each other. A0 pin of controller is connected to Vout of LM35 this pin receives data.

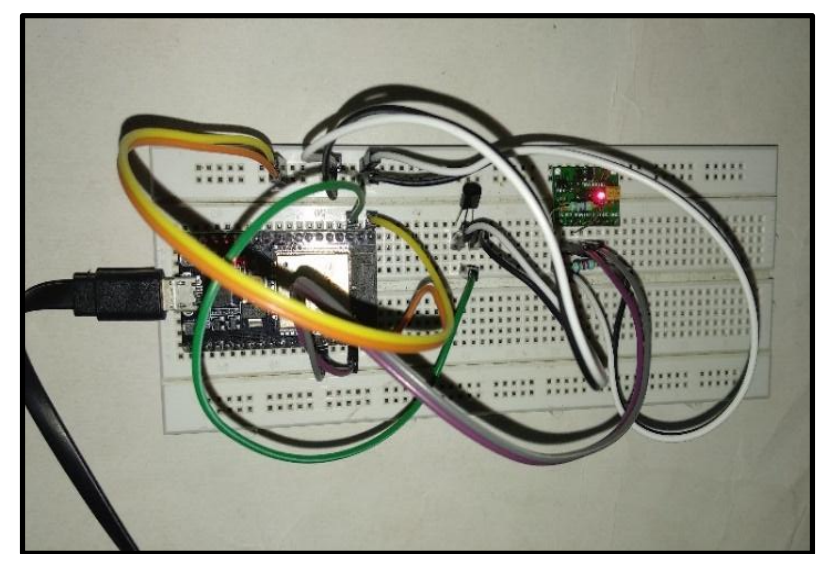

Fig. 2.Hardware connection of covid patient health monitoring system.

The three resistors on MAX30100 are removed and two 4.7k $\Omega$ resistor are connected as pull up resistor between SCL and SDA pins of Pulse Oximeter. The data received from Oximeter and temperature sensor is converted using ADC. The WIFI name and password are provided to the controller are linked using the Authorization key. Authorization key is unique for every project. Blynk provides a graph as well which helps to analyzing a patient's vital information. 


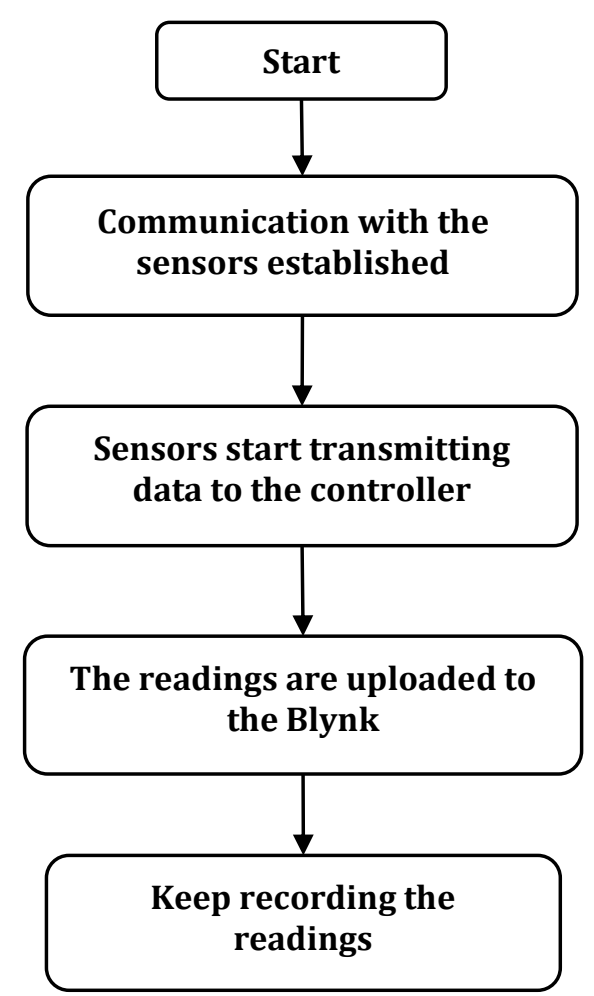

Fig. 3. Flow Chart for covid patient health monitoring system.

\section{Results and Discussions}

The Heart rate (BPM), Blood Oxygen (SpO2) and Temperature are very important in the treatment of COVID patient. Using this information, the treatment and severity of the patient's health can be determined. In fig. 4 we can see the graph of those vitals. This is used for keeping the patient under observation without admitting him in the hospital. As whenever a COVID wave hits there is shortage of beds. So according to the data displayed the doctors can take the required action. The advantages of this project are healing at home is possible, reduces requirement of hospital beds, faster diagnosis, improved treatment, cost reduction. Limitations of this project are internet requirements, other symptoms cannot be monitored

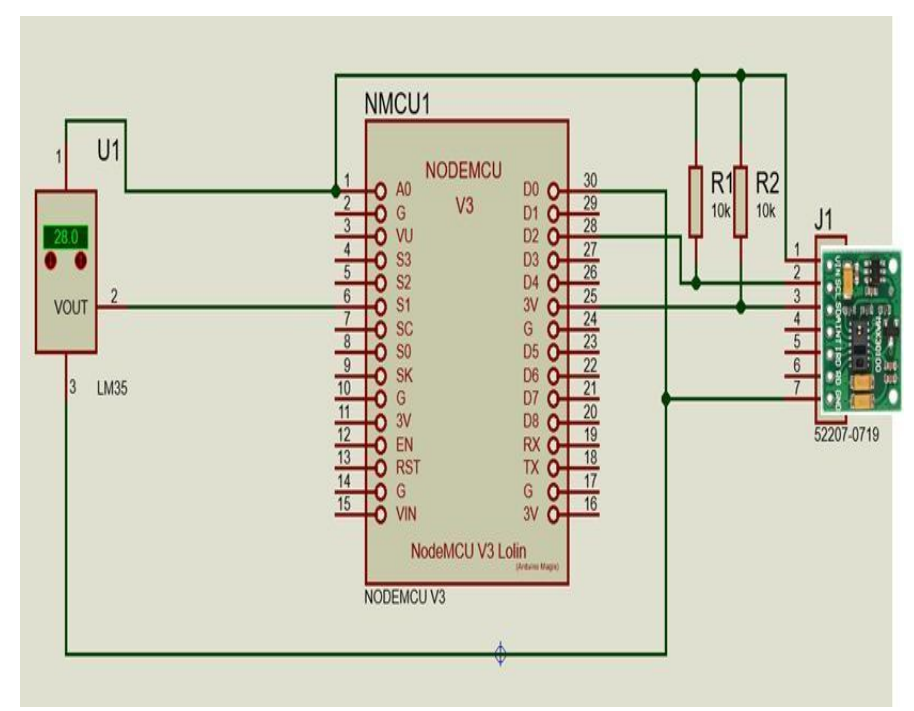

Fig. 4. Circuit Diagram for covid patient health monitoring system. 


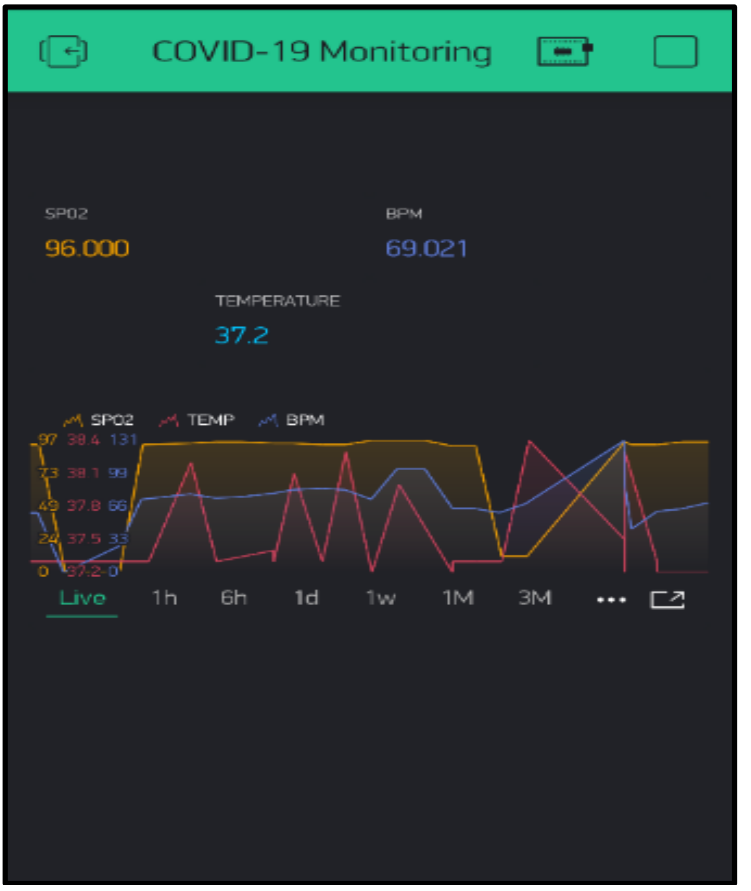

Fig. 5. Blynk App Window Diagram for covid patient health monitoring system.

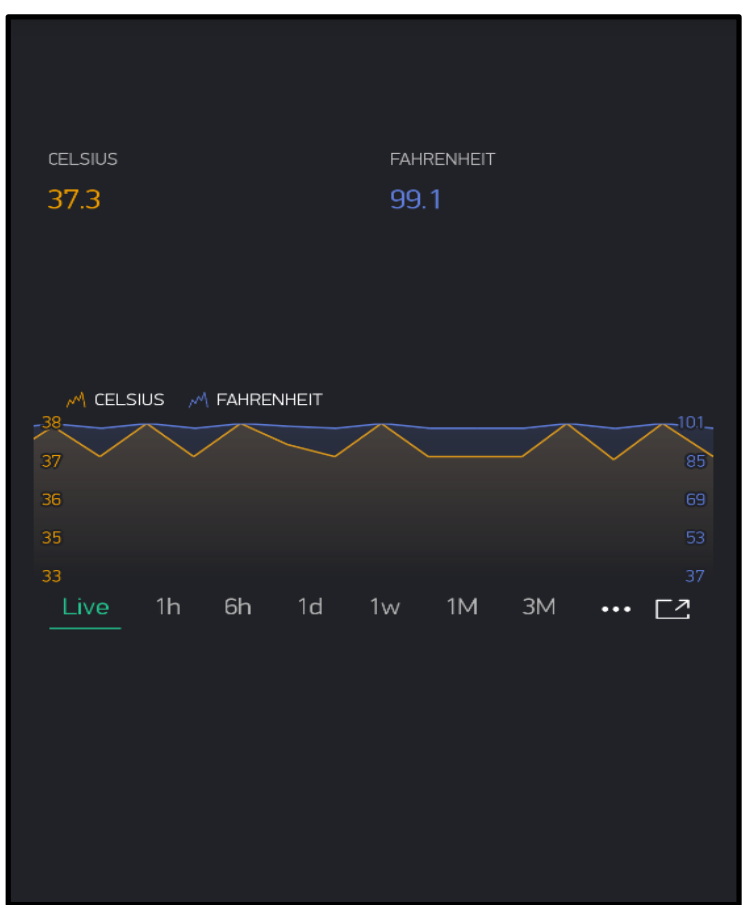

Fig. 6. LM35 Output displayed on Blynk 


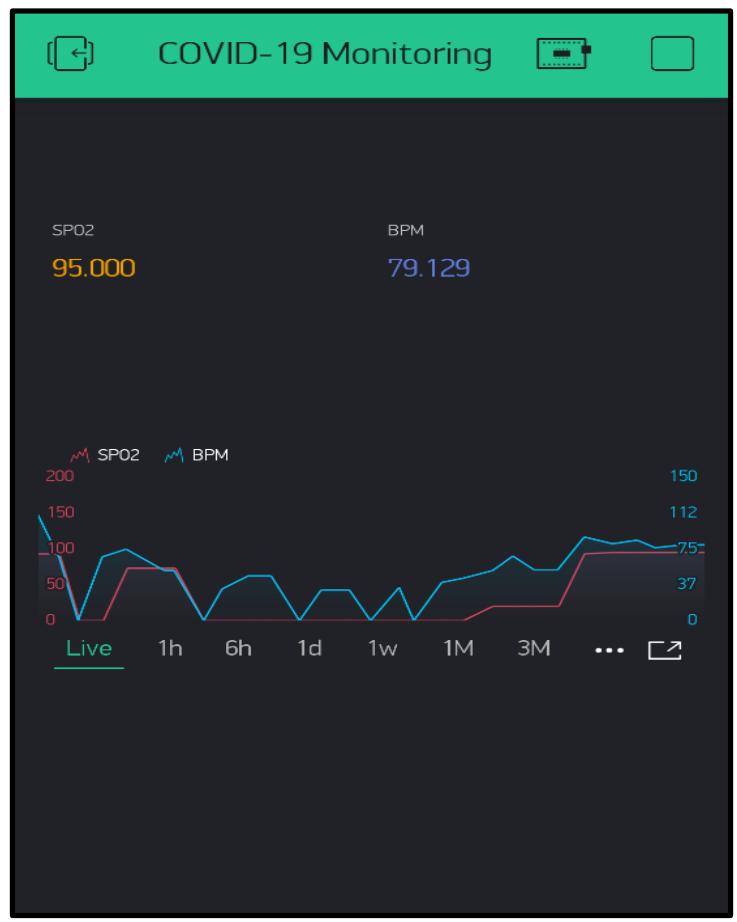

Fig. 7. MAX30100 Pulse Oximeter Output displayed on Blynk.

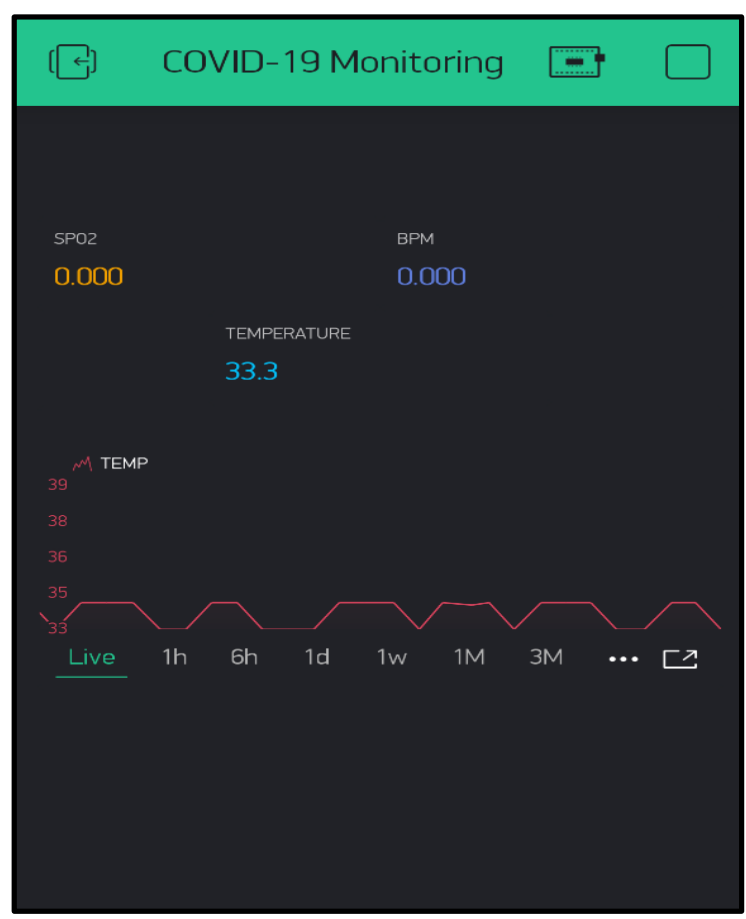

Fig. 8. LM35 Temperature decrement observed in cold condition. 


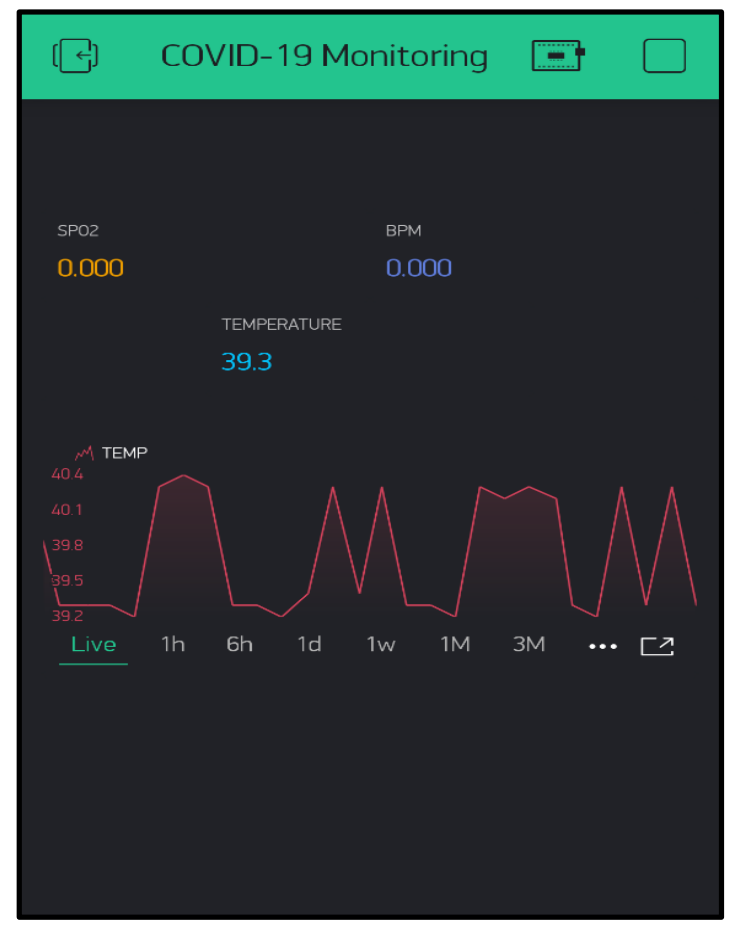

Fig. 9. LM35 Temperature increment observed in hot condition.

\section{Conclusion}

The system introduced COVID-19 patient health monitoring system monitors the basic important signs of patient like heart rate and body temperature. Authenticate medical staff can view and track the data in real time even though the patients perform the test outside the hospital. The developed prototype is very simple to design and use. The developed system will improve current health care system that may protect lots of lives from death.

The early identification of any health problem can help the patient to take necessary emergency measures, which can potentially save the patient's life. IoT can help in this regard. IoT based health monitoring systems can monitor the patients in real-time and warn the patient of any abnormalities. The idea of a smart health monitoring system using the IoT architectures is a novel contribution in the field of medical science and it will reduce health issues and unwanted deaths.

\section{References}

[1] M. A. Mahgoub, O. O. Khalifa, K. Sidek, S. Khan, "Health monitoring system using Pulse Oximeter with remote alert", March 2015, International Conference on Computing, Control, Networking, Electronics and Embedded SystemsEngineering.

[2] M. Shiekh and I. Ameen, "Design of mobile healthcare monitoring system using IoT Technology and Computing", Sept. 2020, 3rd Int. Conf. on Sustainable Engineering Techniques

[3] Y. Khan, D. han, J. Ting, A. C. Aris "Organic Multi-Channel Optoelectronic Sensors for Wearable Health Monitoring", Published in IEEE Access (Volume 7), pp. 128114-128124, September 2019.

[4] A. Angelucci, D. Kuller, A. Aliverti, "A home telemedicine system for continuous respiratory monitoring”, IEEE J Biomed Health inform, Jul 2020.

[5] P. J. Chacon, T. H. da Costa, T. Ghomian, H. Chun Wu, "A Wearable Pulse Oximeter with Wireless Communication and Motion Artifact Tailoring for Continuous Use”, IEEE Transactions on Biomedical Engineering (Volume 66, issue 6), pp. 15051513, October 2018.

[6] T. Hussain, A. Haider, W. Akram, M. Rehman, "Synchronized intermittent mandatory ventilation mode control using pulse oximeter", March 2018, International Conference on Computing Mathematics and Engineering Technologies (iCoMET).

[7] Deepesh K Rathore; Ankita Upmanyu; Deepanshu Lulla "Wireless patient health monitoring system" 2013 International Conference on Signal Processing and Communication (ICSC).

[8] Shola Usha Rani, Antony Ignatious , Bhava Vyasa Hari, Balavishnu V J "Iot Patient Health Monitoring System” Indian Journal of Public Health Research and Development · October 2017.

[9] C. Premalatha, R.P. Keerthana, R. Abarna "HUMAN HEALTH MONITORING SYSTEM" International Research Journal of Engineering and Technology. (Volume: 06 Issue: 01) Jan 2019.

[10] Pedro J. Chacon, Limeng Pu, Tallis Costa"A Wearable Pulse Oximeter With Wireless Communication and Motion Artifact Tailoring For Continuous Use” IEEE TRANSACTIONS ON BIOMEDICAL ENGINEERING (VOL. 66, NO. 6), JUNE 2019.

[11] https://www.who.int/emergencies/diseases/novel- coronavirus-2019/question-and-answers-hub/q-a- detail/coronavirus-disease-covid19\#: :text=symptoms 
[12] https://www.who.int/emergencies/diseases/novel- coronavirus-2019/question-and-answers-hub/q-a- detail/coronavirus-diseasecovid-19\#: :text=protect

[13] MAX30100 Pulse Oximeter and Heart-Rate Sensor IC for Wearable Health Data Sheet.

[14] NodeMCU ESP-32 Microcontroller Data Sheet

\section{Authors' Profiles}

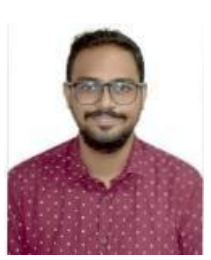

Anurag Tatkare, B.E. and Diploma in Electronics \& Telecommunication, and Diploma in Embedded System. JES, A.C.Patil College of Engineering ,Kharghar, Navi-Mumbai-410210. University of Mumbai.

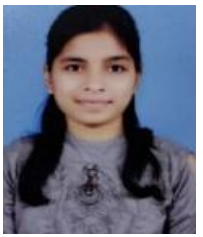

Hemangi Patil, B.E. Electronics and Telecommunication JES, A.C.Patil College of Engineering ,Kharghar, NaviMumbai-410210. University of Mumbai.

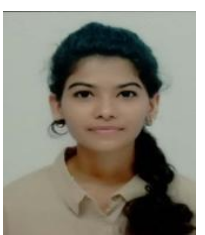

Shreya Warang, B.E. Electronics and Telecommunication JES, A.C.Patil College of Engineering ,Kharghar, Navi-Mumbai-410210. University of Mumbai.

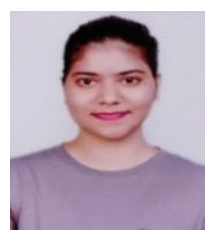

Tejal Salunke, B.E. Electronics and Telecommunication JES, A.C.Patil College of Engineering ,Kharghar, Navi-Mumbai-410210. University of Mumbai.

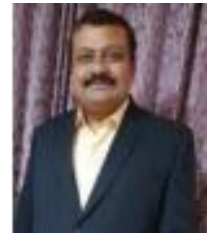

Dipak S. Marathe has submitted his Ph. D Thesis to University of Mumbai, and received the M. Tech. in Electronics from VJTI, Mumbai. He is currently Associate Professor in Electronics and Telecommunication Department at A. C. Patil College of Engineering, Navi-Mumbai, and Maharashtra, India. His research interests include Analog and Digital CMOS VLSI Design, and Wireless Communication.

How to cite this paper: Anurag Tatkare, Hemangi Patil, Tejal Salunke, Shreya Warang, Dipak Marathe, " COVID-19 Patient Health Monitoring System ", International Journal of Engineering and Manufacturing (IJEM), Vol.11, No.5, pp. 48-55, 2021. DOI: 10.5815/ijem.2021.05.05 